\title{
A Hybrid Piezoelectric-Solar Based Power Generation System
}

\author{
Ms. Bhusari Priya Govind ${ }^{1}$, Ms. Chavan Deepika Limchan ${ }^{2}$, Ms. Kadam Pratibha Dattatray ${ }^{3}$,Mr.A.B.Vitekar ${ }^{4}$ \\ Department of E\&TC Engineering, Bharati Vidyapeeth's College Of Engineering For Women, Pune, India ${ }^{1,2,3,4}$
}

\begin{abstract}
This paper implements an efficient way to power generation system, using solar power. Solar energy system is used to collect maximum power from sun. this proposal is to use the solar panels implemented in this project more efficiently and to carry out a realistic experimental approach to enhance the solar output power to a significant level and piezoelectric energy harvesting circuit. In this paper, piezoelectric-based energy harvesting technology is applied to generate electricity from mechanical stress (vibrations). Using piezoelectric material to harvest vibration energy from humans walking, machinery vibrating, or cars moving on a roadway is an area of great interest, because this vibration energy is otherwise untapped. Since movement is everywhere, the ability to capture this energy cheaply would be a significant advancement toward greater efficiency and cleaner energy production. The goal of this experiment is to investigate whether piezoelectricity would be able to provide sufficient source of voltage to charge the parent battery in case of rainy or cloudy days. . This configuration allows the two sources to supply the load separately or simultaneously depending on the availability of the energy sources. This paper implements an efficient way to electrify or generate electricity using solar power and piezoelectric energy harvesting circuit.
\end{abstract}

Keywords: Photovoltaic (PV), Piezoelectric Energy, Full Wave Bridge Rectifier.

\section{I.INTRODUCTION}

Now a days, with increasing concern of global warming and the depletion of fossil fuel reserves, many are looking at sustainable energy solutions to preserve the earth for the future generations. Other than hydro power, vibration and photovoltaic energy holds the most potential to meet our energy demands. Alone, vibration energy is capable of supplying large amounts of power but its presence is highly unpredictable as it can be here one moment and gone in another. Similarly, solar energy is present throughout the day but the solar irradiation levels vary due to sun intensity and unpredictable shadows cast by clouds, birds, trees, etc. The common inherent drawback of vibration and photovoltaic systems are their intermittent natures that make them unreliable.

When a source is unavailable or insufficient in meeting the load demands, the other energy source can compensate for the difference by combining these two intermittent sources.

Solar energy is the viable source of renewable energy over the last two-three decades. It is now used in variety of fields such as industries, domestic purpose. Solar energy system is designed to collect maximum power from sun and to convert into electrical power.[1].

Another form of energy is Vibration energy (mechanical energy) is converted into electric energy by piezoelectric effect. To implement the project more efficiently, the concept of piezoelectricity have been introduced. In this paper, piezoelectric-based energy-harvesting technology is applied to generate electricity from vibration. Piezoelectricity is the electric charge that accumulates in certain solid material in response to applied mechanical stress. The propose system, is to make power generation more sustainable, economical and ecological by utilizing the advancement in the technology[2].
This project introduced two methods and considered its output performance provided input vibrations, by using piezoelectric materials such as PZT for electro mechanical conversion using Mass-spring system as medium of conversion of force from vibrations applied on PZT materials and by using spring-magnet system where relative displacement of magnet with respect to coil, provided input vibrations generates Electromotive force in coil[3].

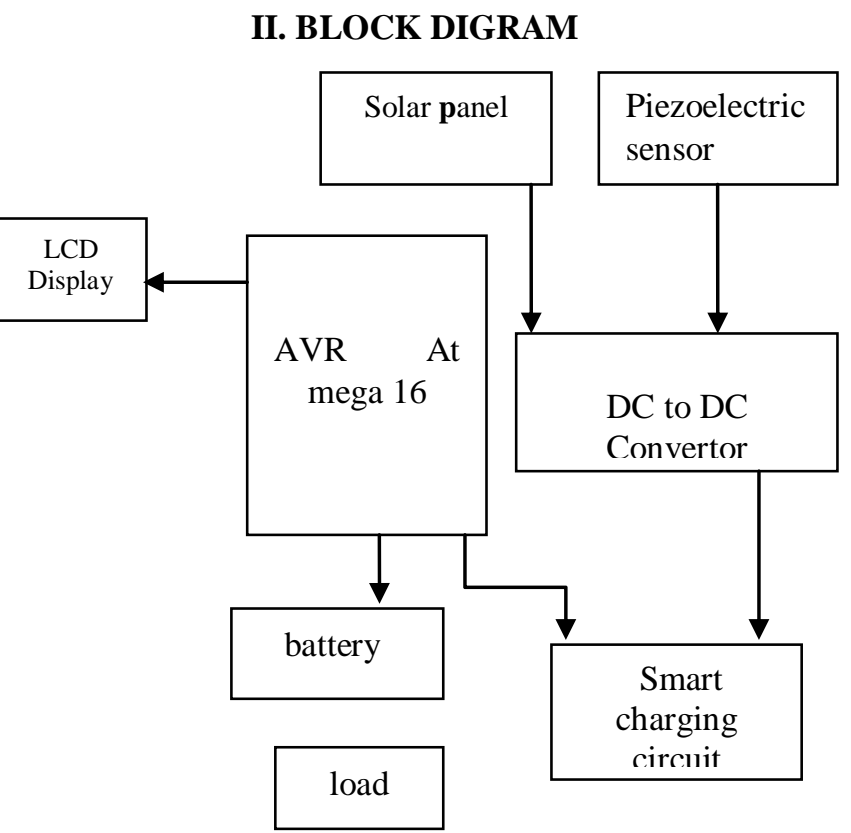




\section{SPECIFICATION}

A] Hardware

1. AVR At mega 16 Microcontroller
2. Solar panel
3. Piezoelectric sensor
4. LCD display
5. Rechargeable battery.
B] Software
Code Vision AVR /AVR Studio AVR ISP Programmer

\section{AVR AT MEGA16 MICROCONTROLLER}

The ATmega16 is 40 pin IC which has four port like port $\mathrm{A}$, port $\mathrm{B}$, port $\mathrm{C}$ and port $\mathrm{D}$. the pin diagram of microcontroller IC is as shown in below figure 3.AT mega16 is 8 bit microcontroller and it is based on RISC architecture it works on $16 \mathrm{MHz}$ frequency. it has low power consumption and inbuilt analog to digital converter. microcontroller execute powerful instruction in single clock cycle. it has main pin are

A] VCC - this pin is use for the supply voltage purpose.

B] GND - this pin is use for Ground purpose.

C] Port A - Port A has inbuilt Analog to Digital converter. which is from pin no. 33 to 40 .

D] Port B - port B is available for pin no. 1 to $8 . i$ it is bidirectional input output port.

E] Port $\mathrm{C}$ - port $\mathrm{C}$ is also bi-direction pin. which is from pin 21 to 29.

F] Port D - port D has timers, interrupts, oscillator input. which from pin no. 13 to 20 .

G] AVCC - it is pin no. 30 which is use for supply voltage for $\mathrm{A} / \mathrm{D}$ converter and $\mathrm{D} / \mathrm{A}$ converter.

$\mathrm{H}] \mathrm{AREF}$ - This is the analog reference pin for the A/D Converter.

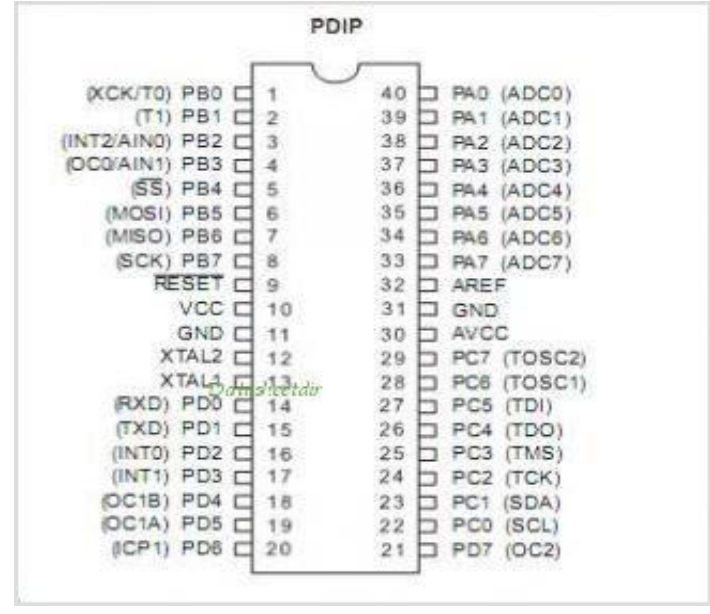

\section{PHOTOVALATIC (PV)}

Solar energy is unsurpassed by any other form of energy. Solar energy was originally coming from sun. Solar cells convert this solar radiation into useful electrical energy and store them in storage such as batteries, but in these cases, it will directly converted to be used for competition. Solar radiation strikes the earth surface and creates the paramount source of alternative energy. Solar panels help to harvest this energy and convert it into usable energy. Solar is an intermittent power source that functions only when the sun is shining. Solar cells or photovoltaic cells are arranged in a grid like pattern on the surface of the solar panel. These solar voltaic cells collect sunlight during the daylight hours and convert it into electricity.

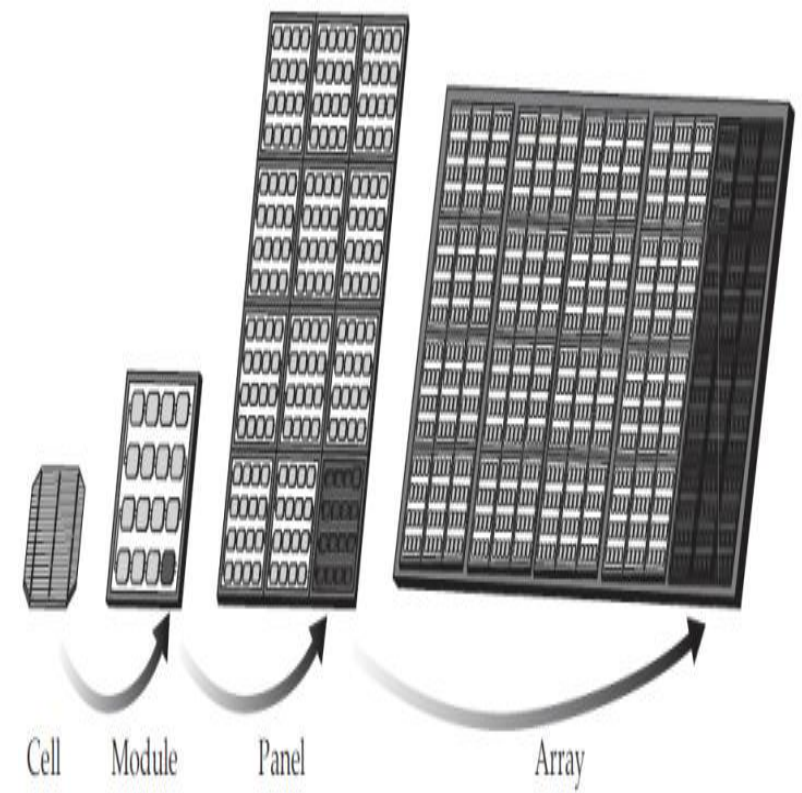

Fig2.1: Components of a PV Array

\subsection{TYPES OF SOLAR PANEL}

1. Mono crystalline silicon panels

2. Polycrystalline silicon panels

3. Amorphous silicon panels

These are the types of solar panel that can be used for project according to their usages. Solar panels are typically 


\section{International Journal of Advanced Research in Computer and Communication Engineering}

Vol. 4, Issue 3, March 2015

constructed with crystalline silicon, and the more expensive gallium a Yrsenide, which is produced exclusively for use in photovoltaic cells.

The process of producing solar energy is a process of converting light (photons) into electrical propulsion known as the photovoltaic effect (PV).

Contained within photon of light contains the number or rate of energy varies depending on the wavelength and spectrum of solar generated.

When the photon is in violation or in contact with the solar panel, solar panels will absorb photons in some degree.

Not all photons are absorbed by the solar panels because it depends on the type of semiconductor materials used to produce the solar panels.

Photon energy at certain levels is able to dissolve the bonding electrons from atoms to produce electricity.

Quantity of the energy produce is difference between materials with other material in the production of solar cells. This energy level is known as band-gap energy which is measured in units of electron-volts.

A material with band-gap energy between $1 \mathrm{eV}$ and $1.8 \mathrm{eV}$ are the best material and has a high efficiency of energy production.

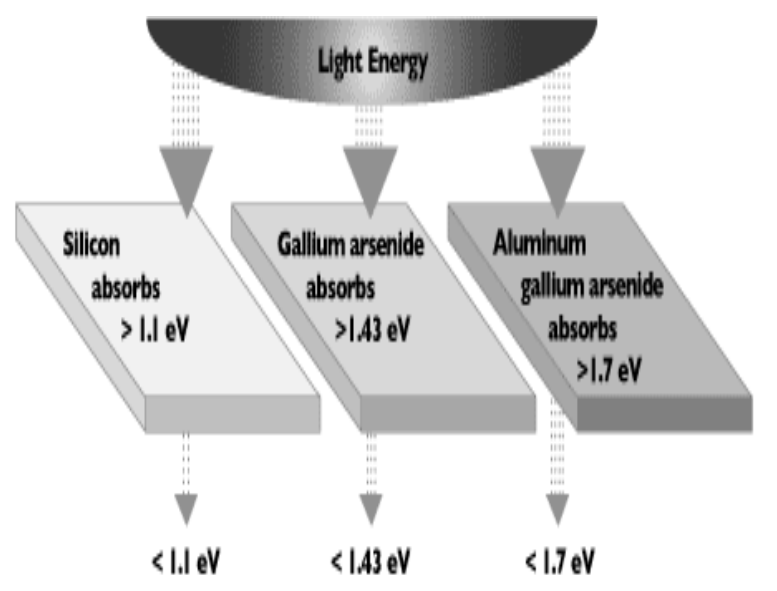

Fig2.2: Band Gap

\subsection{SOLAR PANEL INSTOLLATION}

Solar Panels are typically installed on rooftops, building tops, or stand-alone facilities. It is important to install solar panel so that it gets the most direct sun exposure. These determine solar panel is maximally effective during the testing conducted. To implement, there are several resources in helping properly to set Up and install

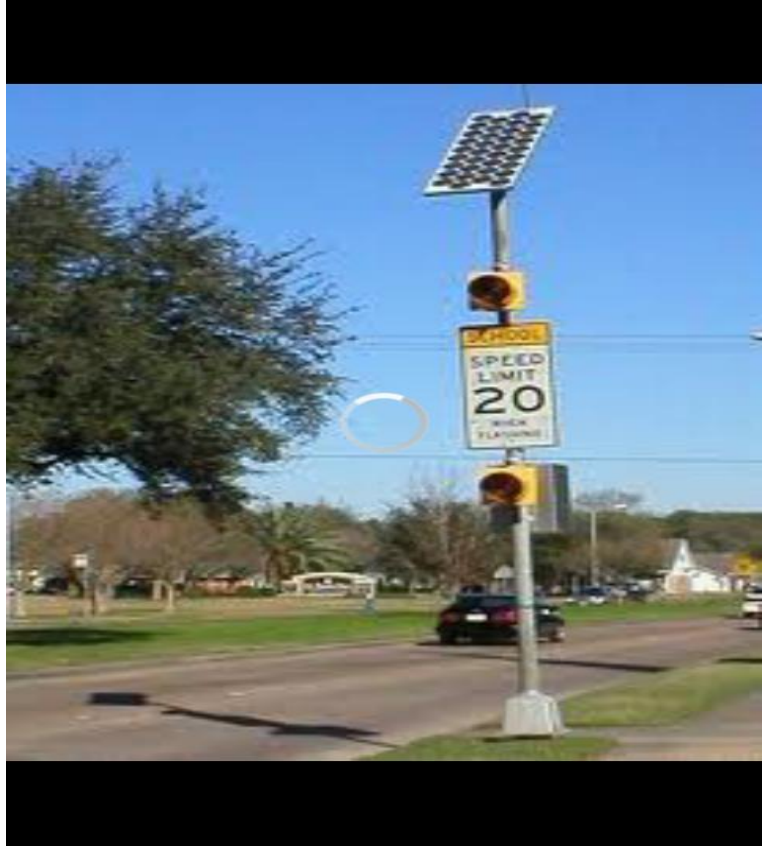

\section{PIEZO-ELECTRIC MATERIAL}

Piezoelectric Energy Harvesting is based upon the piezoelectric effect. The essence of the piezoelectric effect works as follows: by applying a mechanical stress to a crystal, one can generate a voltage or potential energy difference, and thus a current.

\section{Piezoelectric generator principle:-}

The conversion chain starts with a mechanical energy source from vibration. The vibrations are converted into electricity via piezoelectric element. The electricity produced is thereafter formatted by a static converter before supplying a storage system or the load(electrical device).Piezoelectric generators work due to the piezoelectric effect. This is the ability of certain materials to create electrical potential when responding to mechanical changes. To put it more simply, when compressed or expanded or otherwise changing shape a piezoelectric material will output some voltage.

\section{DC to DC CONVERTER}

A buck converter is a voltage step down and current step up converter the simplest way to reduce the voltage of dc supply is to use linear regulator(such as 7805),but linear regulators waste energy as they operate by dissipating excess power as heat. buck converters, on the other hand can be remarkably efficient (95\% or higher for integrated circuits),making them useful for task such as converting the main basic operation of the buck converter has current in an inductor controlled by to switches (usually transistor and a diode). In the idealized converter all the components are consider to be perfect .

\section{LCD DISPLAY}

.LCD $16 \times 12$ it is Liquid crystal Display and it can display 16 character per 2 line. it is very common device use in various circuit and device. this LCD has a two 
register namely command and data. also it will shown combined energy of both sources.

\section{RECHARGABLE BATTARY}

Battery is used for storing the energy come from solar and piezoelectric sensor.

\section{CONCLUSION}

In this study, we have investigated the feasibility of applying piezoelectricity to convert the mechanical vibrations of roadway to useful electricity. We have also investigated the practicability of employing solar concentrators to enhance the output power of the solar panel to a considerable level. We hope that our proposal towards an efficient way to electrify

the streets of all the city corporations under the prevailing "Solar Photovoltaic-Powered LED Street Lighting" project will help to more effectively implement the project within the budget and thereby reducing pressure on conventional power use and current generation

\section{REFERENCES}

[1] R. R. Chowdhury, M. S. Kabir, and M. A. Arafat, "Electrification of Streets of Dhaka City Using Smart Solar System", 2nd International Conference on Informatics, Electronics and Vision, Dhaka, Bangladesh, 2013, pp. 66.

[2] Y. K. Ramadass and A. P. Chandrakasan, "An Efficient Piezoelectric Energy Harvesting Interface Circuit Using a Bias-Flip Rectifier and Shared Inductor", IEEE Journal Of Solid-Sta te Circuits, 2010, pp. 189- 204.

[3] Electrification of Streets of Dhaka City Using Solar and Piezoelectric Energy Rahnuma Rifat Chowdhury 1, Muhammad Salahuddin Kabir_2 _ Department of Electrical, Electronic and Communication Engineering, Military Institute of Science and Technology Dhaka, Bangladesh 3rd on informatics, electronics \& vision 20 